International Journal of Engineering \&Technology, $7(3.12)(2018)$ 632-636
International Journal of Engineering \& Technology
SPC
Website: www.sciencepubco.com/index.php/IJET
Research paper

\title{
ECG Measurements to Emphasize Atrial Potentials Using Modified Limb Lead System
}

\author{
Manikandan $\mathrm{K}^{1^{*}}$, Mohanasundaram $\mathrm{K}^{2}$ \\ ${ }^{1}$ Research Scholar (Anna University), Department of Biomedical Engineering, \\ ${ }^{2}$ Professor, Department of Electrical and Electronics Engineering, \\ ${ }^{1,2}$ Vel Tech Multi Tech Dr.Rangarajan Dr.Sakunthala Engineering College
}

\begin{abstract}
With the advancement in the field of Electrocardiology (ECG), the acquisition of electrical activity of the heart plays an important role in the diagnosis of various cardiovascular diseases. In general, this activity of conduction is acquired using Standard 12 Lead ECG system. Recently, a Modified Limb Lead system has been developed to study the atrial electrical activity for the diagnosis of atrial arrhythmias. The present study is to derive the normal limits of female subjects using Modified Limb Lead (MLL) system. This study was evaluated in 59 female subjects $19.52 \pm 1$ (Mean \pm S.D) and is primarily involved to study atrial potentials with the use of precordial and modified limb lead position. In sinus rhythm female subjects, the $\mathrm{P}$ wave amplitude was $33.06 \pm 21.18 \mu \mathrm{V}$ and the Ta wave amplitude was $20.72 \pm$ $18.16 \mu \mathrm{V}$. The $\mathrm{P}$ wave duration was $94.22 \pm 10.64 \mathrm{~ms}$, the Ta wave duration was $85.51 \pm 17.49 \mathrm{~ms}$. The results show that modifications in the limb electrode placement have significant effect on amplitudes and PR segment which may be of great importance for the assessment of atrial potentials.
\end{abstract}

Index Terms: Atrial arrhythmias, Electro cardiology, Modified Limb Lead System, Sinus rhythm, Standard 12 Lead System.

\section{Introduction}

The standardized placement of limb lead electrodes to acquire the electrocardiogram of an individual was first introduced by Einthoven at al [1]. Where the next level of standardization of the limb leads is been proposed by Wilson et al [2] with the introduction of unipolar limb and the chest leads. Here the combination of electrodes led to the formation of 12 different types of leads (bipolar and unipolar limb leads, chest leads). Then the standardization of the chest (precordial) leads was performed by Barnes et al [3]. Whereas the placement of electrodes became difficult in the case of limb inapproachability so the newer system was proposed in which limb electrodes is been placed on the torso (chest) of an individual. bij Mason et al. [4] described this system for the exercise ECG for testing the stress condition and to avoid the movement artifacts. Then the idea of locating of the limb electrodes over the right side of the sternum was stated by Holzmann et al. [5] that the modification gives more atrial deflection in order to detect atrial fibrillation. This led to a study to visualize the Ta wave (atrial repolarization) which is been obscured by the simultaneous activation of ventricles and the repolarisation of the ventricles this concept is well described in Sivaraman et al. [6-10]. The reason behind it was reported by Jayaraman et al [11] i.e., in general the amplitude of the QRS complex (ventricular depolarization) is much greater than the Ta wave during the acquisition using standard 12 lead system, thereby this makes the Ta wave to hinder. Whereas in Sivaraman et al. $[12,13]$ reports that the great view of unmasked Ta wave is seen by the modification of bipolar limb lead to the right of the sternum. Then the later study of Jayaraman et al [14] proves that there is a major amplitude changes in the leads on comparison between MLL and SLL ECGs and also has an effect on wave amplitudes in the frontal axis whereas does not have any effect in the transverse axis since the precordial leads are left unchanged. The various alternative and special lead systems used in ECG recording are documented by Francis [15]. Madias [16] described ECG low voltage may have many causes, yet they can be classified by their generation (cardiac potential) and their influence over body (extra cardiac potential). Any significant abnormalities on the periphery may cause reversing of the QRS voltage, which in turn reduces amplitudes and time period of $\mathrm{P}$ and $\mathrm{T}$ wave, also their QT intervals, QRS complex and cause many consequences. Even alteration in heart's placement relative to the chest wall and Obesity are serious factors affecting the QRS complex. From the entire study there are many states affecting both healthy (normal) and abnormal subjects. Thus low cardiac volumes and decreased heart thickness and mass has significant effect on LQRSV which decreases amplitude and duration of $\mathrm{P}$ wave, T wave, QRS complex and even QT intervals. Macfarlane et al. [17] has described and created development of ECG database to distinguish the normal limits for South Asians (Dravidians) living in India. The system is mainly monitored and acquired using Standard 12 lead system. Increase and decrease of duration and amplitudes differ according to the origin and also the morphology taken into consideration. QTc is longer in females than upper limit in males. PR is larger in males and it also varies depending in age and gender. A normal distribution was performed using linear regression \& t-test. Analysis clearly describes the range of normal limits to differentiate from the abnormality. 


\section{Methods}

\section{A. Subjects}

Fifty nine healthy female subjects in the range of 18 to 21 years of age were included in this study. The distribution of mean age is $19.52 \pm 1$ (Mean \pm SD). All healthy volunteers are from the Department of Biomedical Engineering in Vel Tech Multi Tech Dr.Rangarajan Dr.Sakunthala Engineering College, Avadi. Nonhypertensive subjects were included in this study. None of the subjects possessed any form of cardiovascular disorders. All the subjects gave consent for participation in this study.

\section{B. Electrode Placement}

The difference in limb electrode placement between standard 12 lead and modified limb lead system is described in table 1 . The precordial leads remain same for both the lead systems. The surface electrodes are placed in supine position under resting condition. The principle behind ECG recording is when the depolarisation wave approaches the lead, it results in positive deflection and when it travels away from the lead, it results in negative deflection. The electrode placements are based on the cardiac vector axis.

The polarity of the modified limb electrode is same as Einthoven triangle [1, 6-9]. The modified limb electrode placement that forms the modified limb lead system is shown in figure 1 . The difference in electrode placement between SLL and MLL system is shown in figure 2 .



Fig. 1: Modified limb electrode placement

Table 1: Difference between SLL and MLL in ElectrodePlacement

\begin{tabular}{|ll|l|l|}
\hline Electrodes & & $\begin{array}{l}\text { Standard limb lead } \\
\text { system }\end{array}$ & $\begin{array}{l}\text { Modified limb lead } \\
\text { system }\end{array}$ \\
\hline $\begin{array}{l}\text { Right Arm } \\
\text { electrode }\end{array}$ & (RA) & $\begin{array}{l}\text { placed in the right } \\
\text { arm between } \\
\text { shoulder and wrist }\end{array}$ & $\begin{array}{l}\text { placed on the } 3^{\text {rd }} \text { right } \\
\text { intercostal } \\
\text { space, } \\
\text { llightly left of the mid } \\
\text { clavicular line }\end{array}$ \\
\hline $\begin{array}{l}\text { Left Arm } \\
\text { electrode }\end{array}$ & (LA) & $\begin{array}{l}\text { placed in the left } \\
\text { arm between } \\
\text { shoulder and wrist }\end{array}$ & $\begin{array}{l}\text { placed on the 5 } 5^{\text {th }} \text { right } \\
\text { intercostal } \\
\text { slightly right of the mid } \\
\text { clavicular line }\end{array}$ \\
\hline $\begin{array}{l}\text { Right Leg } \\
\text { electrode }\end{array}$ & (RL) & $\begin{array}{l}\text { placed in the right } \\
\text { ankle (reference) }\end{array}$ & $\begin{array}{l}\text { placed in the right ankle } \\
\text { (reference) }\end{array}$ \\
\hline $\begin{array}{l}\text { Left Leg } \\
\text { electrode }\end{array}$ & (LL) & $\begin{array}{l}\text { placed on the 5 right } \\
\text { placed in the left } \\
\text { ankle }\end{array}$ & $\begin{array}{l}\text { thercostal space exactly } \\
\text { in the mid clavicular } \\
\text { line }\end{array}$ \\
\hline
\end{tabular}

\section{Data Acquisition and Analysis}

ECG samples are acquired in supine position using Standard 12 Lead and Modified Limb Lead system. $\mathrm{Ag} / \mathrm{AgCl}$ surface electrodes for limbs and suction cup electrodes for chest are employed for the recording purpose. The acquisition is performed with the help of digital electrocardiograph (EDAN SE-1010 PC ECG system version 2.0, EDAN INSTRUMENTS, INC) operating at 1000 samples / second / channel with a frequency response of $0.05 \mathrm{~Hz}$ to $150 \mathrm{~Hz}(-3 \mathrm{~dB})$. ECGs could be recorded at gain from $2.5 \mathrm{~mm} / \mathrm{mV}$ to $20 \mathrm{~mm} / \mathrm{mV}$ with a variable paper speed from $5 \mathrm{~mm} / \mathrm{s}$ to $50 \mathrm{~mm} / \mathrm{s}$. In this study, the ECGs were recorded for 60 seconds each with paper speed of $25 \mathrm{~mm} / \mathrm{s}$ and gain of $10 \mathrm{~mm} / \mathrm{mV}$. The records were then manually measured for comparative analysis.

In MLL ECG traces, the onset of $P$ wave to the end of observable Ta wave is measured manually and is referred to as P-Ta interval [8]. The end of $\mathrm{P}$ wave to the end of observable Ta wave is known as Ta duration. 


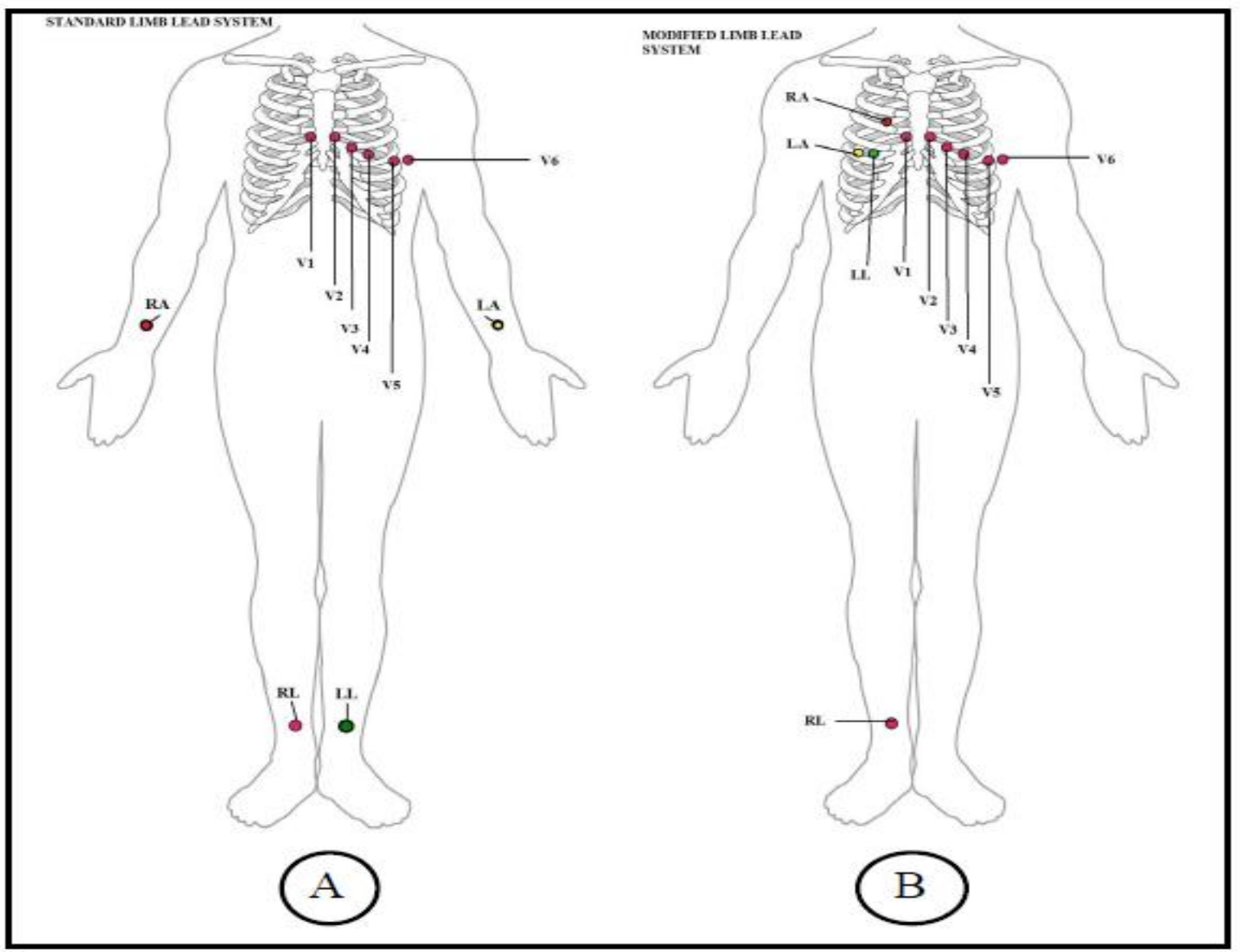

Fig. 2: Difference in electrode placement between SLL \& MLL system

(A - denotes the Standard Limb Lead Placement ; B - denotes the Modified Limb Lead Placement)

\section{Statistical Analysis}

The ECG traces are statistically analyzed using WinStat in Excel for Windows office 2007. The measurements such as amplitude and time duration are expressed in terms of Mean \pm Standard deviation. The student t-test was performed to return the probability value for dependent and independent variables. It determines the extent at which the differences are significant (low $P$ value). All the values are one sided with $p<0.5$ were found to be statistically significant.

\section{Results}

The standard and modified limb lead ECGs were recorded at standard paper speed of $25 \mathrm{~mm} / \mathrm{s}$ with gain $10 \mathrm{~mm} / \mathrm{mV}$ in supine position for healthy female subjects. The standard 12 lead ECG of a female subject recorded at standard paper speed using EDAN PC ECG system is shown in figure 3.

In standard 12 lead ECG traces, the amplitude of $\mathrm{P}$ wave is much smaller and the PR segment is an iso-electric line in all the leads. The $\mathrm{R}$ wave amplitude is higher in all the leads. The presence of atrial repolarisation (Ta wave) remains obscure in QRS complex when recorded in standard limb lead (SLL) system [7,8]. The MLL ECG of the same female subject recorded using EDAN PC ECG system is shown in figure 4.

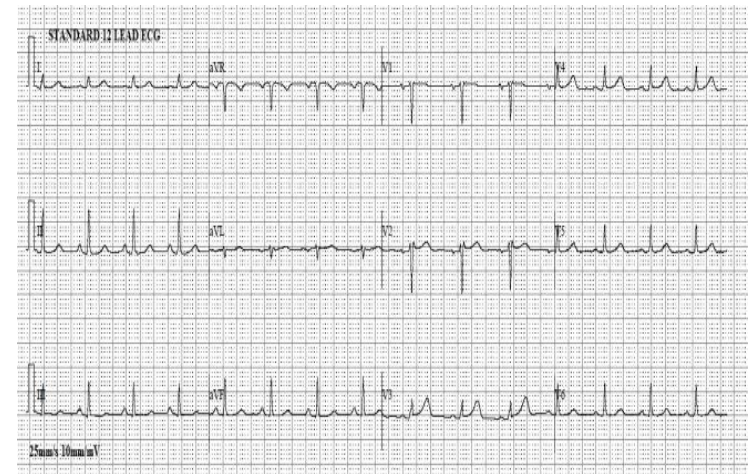

Fig. 3: Sinus rhythm of a female (20 yrs old) subject recorded at $25 \mathrm{~mm} / \mathrm{s}$ and $10 \mathrm{~mm} / \mathrm{mV}$ using Standard Limb Lead system (SLL)

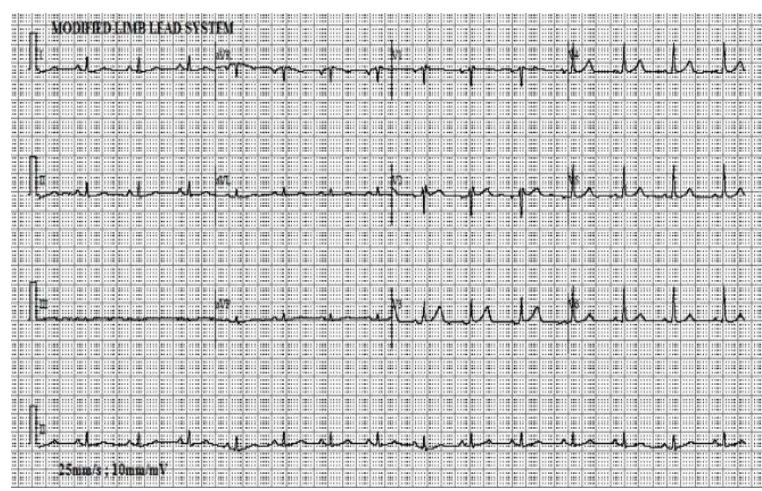

Fig. 4: Sinus rhythm of a female (20 yrs old) subject recorded at $25 \mathrm{~mm} / \mathrm{s}$ and $10 \mathrm{~mm} / \mathrm{mV}$ using Modified Limb Lead system (MLL), which clearly shows the presence of atrial Ta wave

Due to the modifications in the limb lead positions, the observable $\mathrm{P}$ wave has greater amplitude than SLL. The MLL ECG traces 


\section{Conclusion}

The standard 12 lead ECG system has limitations in the detection of atrial potentials. Hence, the modification of limb leads are adopted to produce significant changes in atrial potentials (amplitude and duration) compared to standard limb lead system. This modification focusses on atrial depolarization and repolarization waves which plays a key role in early detection of atrial arrhythmias

\section{Acknowledgment}

We would like to extend our special thanks to the Students of Biomedical Engineering Department for extending their arms and showing their immense support in our project.

\section{References}

[1] Einthoven W. "The different forms of the human electrocardiogram and their signification" Lancet 1912; 1:853-61.

[2] Wilson FN, Johnston FD, MacLeod AG, Baker PS. "Electrocardiograms that represent the potential variations of a single electrode". Am Heart J 1934; 9: 447-71.

[3] Barnes A, Pardee HEB, White PD, Wilson FN, Wolferth CC. "Standardisation of precordial leads"- Supplementary report. Am Heart J 1938; 15: 235-9.

[4] Mason RE, Likar I. "A new system of multiple-lead exercise electrocardiography”. Am Heart J 1966; 71; 196-205.

[5] Holzmann M. "Die klinische Bedeutung der anterioren posterioren Brustwandableitungen im Elkrulardiogramm Arch".Kreisl Forsch 1937; $1: 1$.

[6] Sivaraman J, Uma G, Venkatesan S, Umapathy M, Dhandapani VE. "Normal limits of ECG measurements related to atrial activity using a modified limb lead system". Anatol J Cardiol. 15 (2015) 26.

[7] Sivaraman J, Uma G, Venkatesan S, Umapathy M, Dhandapani VE. "A novel approach to determine atrial repolarisation in electrocardiograms". J Electrocardiol 2013; 46; e1.

[8] Sivaraman J,Uma, G,Venkatesan S,Umapath M, Ravi M.S, "Unmasking of atrial repolarization waves using a simple modified limb lead system, Anatol. J. Cardiol. 15 (2015) 605-610.

[9] Sivaraman J, Venkatesan S,Periyasamy R, Justin Joseph, Ravi Marimuthu Shanmugam, "Modified limb lead ECG system effects on electrocardiographic wave amplitudes and frontal plane axis in sinus rhythm subjects", Anatolian journal of cardiology 17 (2017) 46-54.

[10] Sivaraman J,Uma, G,Venkatesan S,Umapath M,,Keshav Kumar.N, A study on atrial Ta wave morphology in healthy subjects: An approach using $\mathrm{P}$ wave signal-averaging method. Journal of Medical Imaging and Health Informatics, 2014.Vol. 4(5): 675-680.

[11] Sivaraman J,Uma G, Umapathy M. A modified chest leads for minimization of ventricular activity in normal electrocardiograms. Proc IEEE Int Conf on Biomedical Engineering, Penang, Malaysia, 2012. pp. 79-82.

[12] Sivaraman J,Uma G,Angley P.L,Umapathy M, Venkatesan S,Palanikumar G. A study on stability analysis of atrial repolarization variability using ARX model in sinus rhythm and atrial tachycardia ECGs. Computer Methods and Programs in Medicine, 137, (2016), 341-351.

[13] Sivaraman J, Saah electrocardiography: An insight toward micro waveform of atrioventricular node and His bundle potentials. Anatolian Journal of Cardiology, Vol. 18(2): 115-115, 2017.

[14] Sivaraman J, Renu John. Effects of sinus rhythm on atrial ECG components using modified limb lead system. Proc $4^{\text {th }}$ IEEE Int Conference on Signal Processing, Computing and Control, JUIT, Himachal Pradesh, pp. 527-530, 2017.

[15] Johnson Francis, "ECG Monitoring Leads and Special Leads", Indian Pacing and Electrophysiology Journal, 16 (2016) 92-95.

[16] Madias J E, MD , "Low QRS voltage and its causes", Journal of Electrocardiology 41 (2008) 498-500

[17] Macfarlane Peter W., Lloyd Suzanne M., Singh Dilbag, Hamde Satish, Clark Elaine, Devine Brian, Francq Bernard G., Kumar Vinod, "Normal limits of the electrocardiogram in Indians", Journal of Electrocardiology (2015), 04-13. 